\title{
An obligation to provide abortion services: what happens when physicians refuse?
}

\author{
Christopher Meyers and Robert D Woods \\ Department of Philosophy and Religious Studies, Califormia State \\ University, Bakersfield, California
}

\begin{abstract}
Access to abortion services in the United States continues to decline. It does so not because of significant changes in legislation or court rulings but because fewer and fewer physicians wish to perform abortions and because most states now have "conscientious objection" legislation that makes it easy for physicians to refuse to do so. We argue in this paper that physicians have an obligation to perform all socially sanctioned medical services, including abortions, and thus that the burden of justification lies upon those who wish to be excused from that obligation. That is, such persons should have to show how requiring them to perform abortions would represent a serious threat to their fundamental moral or religious beliefs. We use current California law as an example of legislation that does not take physicians' obligations into account and thus allows them too easily to declare conscientious objection.
\end{abstract}

The ethics committee at a county hospital in California recently faced the following dilemma:

The county had a state-mandated legal obligation to provide abortion services for two population groups those incarcerated in the county penal facility and those deemed incompetent to make their own medical decisions. The county had chosen to provide these services through its public hospital, which had, in turn, subcontracted with a local private obstetrician to perform most of the abortions.

When this obstetrician's services became unavailable, the hospital searched in vain for another private physician willing to cover the service. Realizing this meant that his staff would have to fill the void, the chair of the hospital's obstetrics and gynecology department approached the ethics committee, looking "to relieve the residents and faculty of this burden". Discussion revealed that of the eight residents on staff, only one was willing to perform elective abortions. And, according to the chair, none were qualified to perform an unassisted second

\section{Key words}

Abortion; abortion services; physician obligations; conscientious objection. trimester procedure. Compounding this shortage was a reluctance on the part of the faculty, a reluctance that ranged from "flat refusal" to "strong distaste".

After obtaining the relevant facts, the committee proceeded to provide the chair with information from California's "conscience clause" legislation." This legislation allows health care workers to opt out of providing abortion services if they sign a written declaration stating they hold "a moral, ethical, or religious objection". This information solved the chair's dilemma; he and all the members of his staff promptly submitted the appropriate statements and were thereby legally excused from the obligation.

But now the hospital was unable to fulfil its legal duty. That is, the hospital, as the county agency providing state-mandated health care, was obliged to maintain abortion services but had no one willing and qualified to do so. A local clinic agreed to take the incompetent patients but not the inmates, fearing the presence of women in shackles being guarded by an armed deputy sheriff would intimidate their other clients. ${ }^{2}$ The only other option was to transport the inmates to a clinic in a major metropolitan area some two hours away. But this proved to be prohibitively expensive, given the need for transportation and guards.

In short, the hospital and the county were legally stuck between a rock and a hard place. They had one state law mandating that they provide abortion services and another state law resulting, in practice, in an absence of physicians willing to perform them.

That there were not enough physicians willing to provide abortion services is not unique to this hospital. Although the demand for abortions remains fairly constant, fewer and fewer physicians are willing to perform them or even to learn the relevant skills; indeed, as of 1991, "eighty-three per cent of US counties [had] no abortion provider". Thus, while the committee was able to resolve the problem in this case - through creative arrangements with the clinic and through hiring a faculty member willing to perform abortions - it will undoubtedly arise again, if not at this hospital then at some other public facility. 
It will arise again because California's conscience clause, like similar clauses in other states, ${ }^{4}$ places the dilemma solely in the context of competing rights, with no inclusion of concomitant obligations. That is, the law sees the problem only as an example of a conflict between the right of physicians ${ }^{5}$ freely to choose which procedures they can morally tolerate versus the right of access to abortion services. An analysis of these rights is no doubt important. But such an analysis will come up short if it does not also include consideration of how obligations, particularly status or role-engendered obligations, weigh against these rights.

In this paper we thus provide a critique of the California conscience clause and thereby also attempt to address the general issue of when it is appropriate for physicians to declare conscientious objection. While we strongly support the right of an individual to opt out of participation in activities she or he finds morally repugnant, we do not believe the California conscience clause provides appropriate means for doing this. We argue that the law is seriously flawed because, first, it does not take adequate account of physicians' moral obligations to provide services and, second, because it simplifies the process of moral decision-making to the point where it is rendered, at best, trivial. After considering the benefits enjoyed by US physicians, we contend that they have a prima facie obligation to provide services, including abortion services, and thus that the burden of proof lies upon them to justify being exempted from this duty. We conclude with some suggested changes to the conscience clause, changes that would include consideration of physicians' duties, show greater respect for moral decision-making, and still protect genuine conscience-based moral decisions.

The issues raised here clearly extend beyond abortion and beyond California. We focus on abortion and California's conscience clause because we believe the problems raised in our case serve best to exemplify the extent to which physicians have an obligation to provide care beyond that typically acknowledged. The provision of abortion services represents a paradigm example of the conflict between individual rights and community needs. That is, it involves the conflict between an individual's right to avoid participating in activities she deems morally repugnant and the right of the community to have socially sanctioned medical services made available. While similar consciencebased dilemmas exist in such issues as right to die and living will statutes, ${ }^{6}$ the provision of care to Medicaid patients, ${ }^{7}$ and the use of physicians to provide lethal injections in capital punishment, ${ }^{8}$ none of these carry with them such a direct conflict between physician rights, patient rights, and physician obligations. ${ }^{9}$

Also, the number of physicians willing to perform abortion services has declined, in part, because it has become increasingly risky to do so. As the cases of David Gunn and John Britton ${ }^{10}$ reveal, there is a genuine, if unlikely, threat to personal safety. And there is an even greater threat of harassment and intimidation, including anonymous calls and mailings and picketers at both work and home. Thus if an obligation to provide services can be established on this issue, it would clearly extend to other, less risky but still undesirable - to some - medical procedures.

Finally, the problem is exacerbated in California, and a number of other states, by conflicting laws. In addition to the conscience clause, there are additional laws and regulations which require counties (and thus typically county hospitals) to make such services available to certain populations.

\section{CONFLICTING LAWS AND REGULATIONS}

While US federal courts continue to tinker with the precise meaning of the reproductive and privacy rights emerging from Griswold, ${ }^{11}$ and Roe, ${ }^{12}$ the issues have, for twenty-plus years now, been fairly well settled in California. California law provides both a negative right against governmental interference in activities deemed to fall under privacy protections, ${ }^{13}$ and a positive right, at least for certain population groups, to medical services, including those related to family planning. ${ }^{14}$

California thus gives explicit constitutional and regulatory protection to both a negative right of $\stackrel{\mathbb{Q}}{\alpha}$ privacy and a positive right of autonomy. The state also thereby explicitly guarantees, at least in theory, that abortion services will be made accessible to persons in the protected classes. Through these guarantees the state also acquires the corresponding obligation to ensure the availability and timely provision of such services.

In competition with these rights, however, is the right of physicians to declare conscientious objection to engaging in medical procedures that run contrary to deeply held moral or religious scruples. Hence the rub. On the one hand, California grants individuals $\frac{D}{2}$ the right to determine, without state interference, their own family planning activities and further o strives to secure access to the appropriate health care services for its otherwise compromised citizens; on the other hand, California also allows health $\omega$ care workers to declare conscientious objection to providing abortion services, thereby creating the $\stackrel{0}{\simeq}$

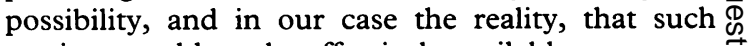
services would not be effectively available.

\section{THE OBLIGATION TO PROVIDE SERVICES}

Part of the reason the county had no means of fulfill-

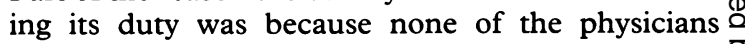
involved believed they had an obligation to perform abortions. In their minds they were free to choose of which activities they wished to practise, so long as there were no laws or regulations to the contrary and

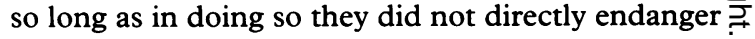


others. The principle of liberty, this argument holds, should be the guiding principle, binding unless one justifies its violation. ${ }^{15}$

Our contention is that the liberty principle is not paramount here because an appeal to it ignores the crucially important social roles and resources that shape contemporary US medicine and society. We believe, in fact, that physicians have a prima facie obligation to provide services. Thus the burden of proof lies with those who wish to be excused from that obligation.

Physicians have this obligation, we contend, because the image of them as unbeholden free agents is a myth. Physicians are, in fact, deeply indebted to society, an indebtedness that brings with it a strict obligation to provide vital and socially sanctioned medical services. ${ }^{16}$ With this obligation comes the need to justify why one should be exempted from providing such services.

The obligation to provide service comes from two sources: 1) The ways in which physicians receive extraordinary social benefits, and 2) The social harms that would be suffered should the service not be provided. Addressing the second reason first, while we acknowledge that our society has not reached anywhere near unanimity of opinion on abortion rights, there has long been a strong majority opinion that women should have the right to determine the course of their pregnancies, at least within certain, mainly developmental, parameters. There seems also to be a consensus, confirmed in recent court rulings, ${ }^{17}$ that undue obstacles should not be placed in the path of women attempting to exercise their reproductive rights. Should abortion services become wholly unavailable to certain segments of society, particularly for relatively trivial reasons, an undue burden clearly would be present, and thus a substantial social harm would accrue.

With regard to the extraordinary social benefits physicians currently enjoy, there are at least five worth noting. First, all physicians trained in the United States receive considerable support in taxpayer-provided educational dollars. For example, in 1990 the US Department of Health and Human Services alone provided $\$ 236,300,000$ in funding for college and postgraduate programmes in health and professional training. ${ }^{18}$

Second, as the California Business and Professions Code explicitly states, professional licensure is a "privilege", not a "right" or "entitlement". ${ }^{19}$ And, as a privilege, it is subject to appropriate state oversight and regulation.

Third, in part because of the state licensing process, physicians have been granted a monopoly on most types of medical care. With such a monopoly comes an enhanced obligation to provide those services society has deemed valuable. In the case of abortion, as our example acutely reveals, women have no alternative source for treatment should physicians succeed in acquiring exemption. ${ }^{20}$
Fourth, physicians enjoy both economic benefit in 1994 the mean net annual income for obstetricians in the United States was $\$ 221,800^{15-18}$ - and lofty social status. With this wealth and prestige comes a special commitment to the society that confirms, and pays for, those advantages.

And fifth, in this case the physicians were all employed at a taxpayer-funded institution; ie, they received their salaries, in part, from some of the very women they refused to treat.

While not all physicians work for public hospitals or clinics and not all receive compensation in the range of a quarter of a million dollars a year, all do nonetheless receive social benefits far beyond those of the average person. We therefore propose that there must be correspondingly powerful justifications given in order to be exempted from the obligation to provide socially valued and legally sanctioned medical services, including abortion services. Accepting this does not negate physicians' right to make free, conscience-based choices regarding what types of care they shall provide and to whom. Our claim is simply that the burden falls upon the physician to show that her conscience is indeed threatened. It is she who appeals for exception to an otherwise existent duty and thus it is she who must justify her position.

\section{PROBLEMS WITH THE CONSCIENCE CLAUSE}

We contend that California's conscience clause has three fundamental flaws. The first is that the clause does not acknowledge physicians' obligations to provide abortion services. Rather, it appears to be grounded in the sort of "free agent" myth discussed in the previous section, ie, that physicians should be able to do whatever they wish. The arguments in the previous section, we hope, reveal why this approach is misguided.

The clause's second flaw is that it makes the process of declaring conscientious objection so simplistic as to trivialise moral decision-making. Recall the requirements of the law: If a health care worker wishes to declare conscientious objection she need only sign a form stating "a moral, ethical, or religious objection" to the procedure. She does not have to give reasons to show that this belief is consistent with other beliefs she holds and practises. Nor is she challenged, made to justify her stance. Rather, she need only do the equivalent of stating that she holds an opinion that the activity is wrong.

The implication of this approach is that, at least on the question of abortion, all beliefs are equally valid. Accepting this subjectivity of values produces, as Langdon Winner argues, "a loss of attention paid to shared reasons for action. When values are looked upon as subjective, ... when basic moral and political ideas are bypassed with such alacrity, any hope of finding a rational basis for common action vanishes. ... [This inevitably results in] a scandalous incompetence in dealing with fundamental, recurring 
questions of human existence: How are we to live together? How can we live gracefully and with justice?"21

We readily grant there is no moral consensus on abortion. We grant also that requiring justification for beliefs implies that valid standards exist for evaluating that justification. And we acknowledge the clear danger that exists in appealing to such standards, ie, that in practice they will simply be the ones held by the society's powerful elite. But to retreat therefore, as we believe the conscience clause does, to the position of no standards, to the view that any moral position is as good as the next, is both to deny the importance and difficulty of careful, rational decision-making and to denigrate our nature as moral agents.

Our culture's rejection of a subjective approach to ethics is revealed, ironically, in the federal law allowing a declaration of conscientious objection to participation in violent military activities. ${ }^{22}$ This statute is considerably more demanding than the California conscience clause; it includes strict guidelines as to what counts as a justifying belief and it demands substantial proof from the petitioner as to the actual existence of this belief. For example, the code specifies that the belief must be strictly religious and may not include "essentially political, sociological, or philosophical views, or a merely personal moral code". And on the question of proof, the courts have uniformly held that each conscientious objection applicant must persuade the draft board that his religious beliefs are personally and, in essence, passionately held. Merely belonging to a religion which holds that war is immoral is insufficient justification. ${ }^{23}$ Instead, the applicant must articulate the basis for his scruple and must demonstrate "sincerity" of belief and consistency in being opposed to all war, not merely this or that war. ${ }^{24}$

No similar test, indeed no test at all, exists in the California conscience clause. No actual justification need be given, only a bare statement that one possesses a scruple against abortion. One need not even specify whether that scruple is moral or religious. Rather, all one must do, in essence, is just say "no".

Indeed, this simplistic process of declaring conscientious objection leads to the clause's third major flaw - that it is too easy to import mixed motives, thereby circumventing the original intent of the law and also thereby enhancing the potential for the legal "Catch 22" described in our case.

The clear, and we believe appropriate, intent of the conscience clause is to protect health care workers from having to perform services which truly would violate their conscience. It is not intended to protect those who would avoid providing abortions out of economic considerations or mere distaste. In practice, however, the bill's broad language allows exactly these kinds of considerations to play a predominant role.
In the case described above, the committee heard a variety of justifications given for why the physicians did not wish to perform abortions, none of which, in our minds, satisfy the intent of the law. For example, $\stackrel{\vec{\rho}}{\oplus}$ one physician viewed participation as creating a potential economic conflict for his private practice in fertility; he worried that his private patients would question his commitment to their goal of producing a child if he was at the same time willing to end the life of another. A second physician saw himself, and wish to be perceived, as a specialist in gynaecology rather than obstetrics. A third candidly admitted that he did not wish to be considered an abortion provider since such services are typically not lucrative. The only protest that came close to meeting the law's intent was the comment that second trimester abortions are "complex and frankly ugly. They are most unpleasant for everyone involved". Even here, though, while there is a hint of a conscience-based 0 scruple lurking in the background, the complaint is presented as an aesthetic, rather than as a moral, objection.

We do not mean to suggest that these physicians were venal, manipulative, or deceitful. They all sincerely did not want to perform abortions and, as the above comments reveal, they were quite candid as to their reasons. The broad language of the conscience clause allows that such a negative desire, combined with a written statement using the statutory language, was all they needed.

\section{A NEW MODEL FOR JUSTIFYING EXEMPTION}

Given these weaknesses in California's conscience clause, a new model is needed which would allow physicians to declare conscientious objection when there is a true crisis of conscience, but which would at the same time take into account both the obligation to provide services and the importance of careful moral decision-making. According to this model, then, a determination of whether an exemption claim is justified would involve a process of ascertaining and weighing the duties and goods extant in the situation. In our case, the cost of allowing exemption entailed both an abrogation of $\widetilde{N}$ the physicians' obligation to treat and the practical N negation of a socially and legally recognised right, a right whose fulfilment, or lack thereof, had the potential for profound impact upon many persons' lives. Thus, we believe, there needed to be a correspondingly profound justification given by those wishing to declare conscientious objection.

While other conscience-based exemptions from social obligations rely upon an institutional process for scrutiny, the existing conscience clause provides no mechanism for determining whether a particular exemption claim is justified. Borrowing, in part, from the guidelines established for the draft board, we therefore recommend a review board be established to evaluate claims of moral objection to providing abortions. 
We recognise that different groups have different means for communicating that a belief is profoundly held; thus the board should be structured so as to represent a diversity of racial, ethnic, and religious beliefs and academic training. Furthermore, so as to reduce the potential power asymmetry between the board and petitioners, it should also include a range of disciplines - medicine, nursing, mental health, social services, chaplaincy - and representatives from the community, including, hopefully, lawyers and ethicists.

The process should begin at an informal level. The board, or perhaps a committee of the board, would meet with the petitioner to discuss the basis and reasons for the claim of exemption. Should the committee not agree, or should the petitioner be dissatisfied with the outcome, the matter would be taken up formally by the full board, at which point the petitioner would have the option to use professional counsel. Finally, in cases of serious dispute, the board's decisions would be reviewable by a court of competent jurisdiction.

We believe such a process would allow for a valid evaluation of petitioners' claims, while also protecting a genuinely conscience-based right to exemption.

To assure uniformity, review boards would need a consistent set of criteria, specific enough to provide guidance, yet with sufficient flexibility to allow for the range of religious and moral beliefs. We, tentatively, propose the following ${ }^{25}$ :

1. The applicant must have a sincere scruple-based objection to the procedure;

2. That scruple must fit within an otherwise coherent system of moral or religious beliefs;

3. The scruple must be consistent with other beliefs and actions with respect to, in particular, activities related to the taking of innocent life;

4. The scruple must be a key component of the petitioner's moral or religious framework, such that its violation, and the concomitant violation of her autonomy, represents a greater moral harm than would the corresponding restriction of abortion rights; 5. All reasonable alternatives must be explored, for example, finding another physician to perform the procedure, with the petitioner merely providing subsequent care and follow-up; and

6. Especially in those cases of public employment, and perhaps in all cases, when exemption is granted some alternative form of public-benefiting professional service should be substituted. ${ }^{26}$

We recognize this is an extensive list, one that requires the petitioner to have and to be able to articulate a well developed and sophisticated moral position. Given the competing rights at stake, we nonetheless contend that the petitioner should be able to satisfy these criteria if her claim of exemption is in fact based on a true crisis of conscience.
We recognise also that the process will likely result in a reduction of the number of health care practitioners who would otherwise claim exemption. Our case suggests that such a result would hardly be unfortunate, since few of the physicians involved appeared to have genuine moral or religious objections. But for those who did, requiring them to articulate the basis of their position seems a minimal imposition, one clearly outweighed by the competing goods at stake.

\section{Acknowledgements}

We wish to thank the participants at various meetings where earlier versions of the paper were read for their many excellent suggestions. We are grateful also to the Kegley Institute of Ethics for providing support for the project and to Legislative Intent Service, Inc for donating time in the collection of legislative historical material.

Christopher Meyers, PhD, is Associate Professor of Philosophy and Director of the Kegley Institute of Ethics. The Revd Robert Woods, $\mathcal{F D}$, is Lecturer in Philosophy, and an Associate of the Kegley Institute of Ethics.

\section{References and notes}

1 California Health and Safety Code: section 2595.

2 Approximately two years after this issue was first presented to the ethics committee, the clinic was destroyed by an as yet unidentified arsonist. It reopened about two months later in a new location.

3 National Abortion Federation. Who will provide? National Abortion Federation, with funding from the American Council for Obstetrics and Gynecology, 1991: 4 .

4 See, for example, Alaska Statutes, title 18, Health, Safety and Housing sec 18.16.010; Arizona Revised Statutes, title 36, Public Health and Safety, sec 36-2151; Louisiana Statutes annotated, title 40, Public Health and Safety, sec 1299.31; Michigan Compiled Laws (ann), Public Health Code, sec 333.20182; Washington Revised Code, title 9, sec 9.02.100.

5 The clause actually applies to all California health care workers. For reasons of space and clarity we restrict our discussion to the rights and obligations held by physicians. Many, but not all, of the arguments below, however, would apply to other health care workers as well.

6 See, for example, California Civil Code, sections 2430-44 concerning durable powers of attorney for health care.

7 See Massachusetts Medical Society $v$ Dukakis (1978) 484 US 896.

8 Bonnie RJ. Medical ethics and the death penalty. Hastings Center Report 1990; 3: 12-8.

9 Right to die and living will issues centre on withholding medical services and Medicaid patient care has a primarily economic focus. Lethal injection cases are fewer in number and therefore less likely to carry with them the strong community need for services.

10 David Gunn and John Britton were physicians who provided abortion services at a number of different 
clinics in various states in the United States. Each was shot and killed, in separate incidents, by anti-abortion activists.

11 Griswold $v$ Conn (1965) 381 US 479, in which the court found a constitutionally protected right to privacy with respect to family planning practices.

12 Roe $v$ Wade (1973) 410 US 113, in which the court found a constitutionally protected right, based in part on privacy, to abortion.

13 The California Constitution, in article I, section 1, expressly includes the right to privacy. California courts have consistently interpreted this right as constitutionally guaranteeing protection against governmental or societal intrusion into, among other things, health care decisions.

14 This right is exemplified in two regulations - section 5325.1 of the Welfare and Institutions Code (which gives wards of the state access to their family planning needs, including abortions) and title 15 of the California Code of Regulations (which grants, with certain qualification, incarcerated pregnant women the right to receive, at public expense, an abortion or other family planning service).

15 Under some definitions, this situation would not even qualify as one requiring conscientious objection. (See, for example, Rawls J. A theory of justice. Cambridge: Harvard University Press, 1971: 368-71.) We reject such an approach as being too narrow in its conception of what qualifies as an obligation to society.

16 The locus of current debate regarding the extent of physicians' obligations to provide services is centred in whether they have a duty to treat HIV-positive patients. Although the issues here vary somewhat from our concern, the discussion does provide general insight into the problem. See, for example, multiple authors. AIDS: The responsibilities of health professionals. Special supplement to Hastings Center Report 1988; 2. See also the follow-up essay by Daniels N. Duty to treat or right to refuse. Hastings Center Report 1991; 2: 36-46. For a broader discussion of conscience-based appeals in medicine, see Blustein J. Doing what the patient orders: maintaining integrity in the doctor-patient relationship. Bioethics 1993; 4: 289-314.
17 Planned Parenthood of Southeastern Pennsylvania $v$ Casey, (1992) 112 US 2791, specifically with reference to the spousal notification clause.

18 Anonymous. Statistical Abstract of the US. Washington DC: Department of Commerce, Bureau of the Census, $\stackrel{\vec{P}}{+}$ Economics and Statistics Administration, Government Printing Office, 1991. Washington DC.

19 Sections $2051 \mathrm{ff}$. See also Lawton $v$ Board of Medical $\overline{\bar{c}}$ Examiners (1956) 143 Cal app 2d 256.

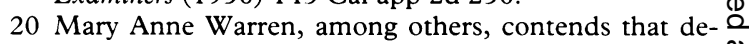
monopolising these services represents the best solution to the problem. (Warren MA. Unpublished observa- $\vec{\circ}$ tions presented in response to this work during the Pacific Division Meetings of the American $\vec{\omega}$ Philosophical Association, 1992, Portland, Oregon). We believe that this would reduce, but not eliminate, the problem, since other health care workers could and likely would also declare conscientious objection. Also, N we do not believe the American Medical Association ? would accept such a de-monopolisation and the precedent it would represent.

21 Winner L. The whale and the reactor: a search for limits in 윽 an age of high technology. Chicago: University of Chicago Press, 1986: 159, 162.

22 Fifty United States Code appendix, section 456(j). We 을 recognize that military conscription is not a perfect analogy to abortion services. We contend, though, that they have key similarities. Both involve issues of deep moral import, both involve large segments of the population, and both involve decisions with life or death consequences.

23 Gillete $v$ US (1971) 401 US 437; and Sicurella v US (1955) 348 US 395.

24 Sicurella $v$ US and US $v$ Spiro $(1967,3 \mathrm{~d}$ Cir) $384 \mathrm{~F} 2 \mathrm{~d}$ 159 , cert den at 390 US 956.

25 Taken in part from the California Supreme Court test of whether proposed restriction of rights is supportable, rooted originally in Committee to Defend Reproductive Rights $v$ Myers.

26 The goal here is to require some service that is both of comparable social benefit and, to most physicians, similarly "distasteful". Thus our tentative suggestion would be for twenty hours per year of indigent medical services. 